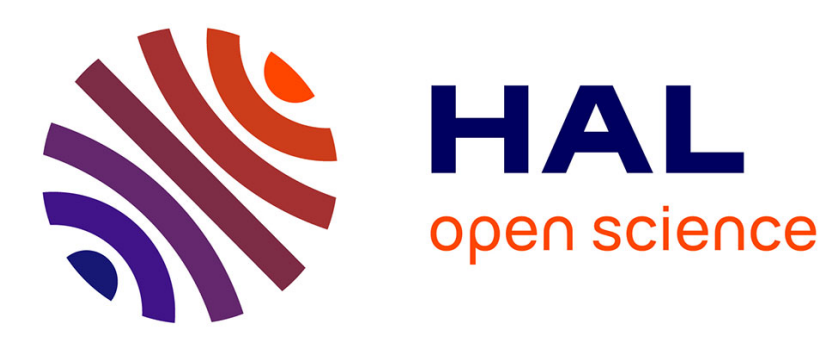

\title{
Numerical intelligence for mobility and communication: Tendencies in automatics and control
}

\author{
Vincent Vigneron, Dominique Gruyer, Saïd Mammar
}

\section{To cite this version:}

Vincent Vigneron, Dominique Gruyer, Saïd Mammar. Numerical intelligence for mobility and communication: Tendencies in automatics and control. Journal of Intelligent Systems, 2014, 23 (2), pp.109-111. 10.1515/jisys-2014-0066 . hal-00985776

\section{HAL Id: hal-00985776 https://hal.science/hal-00985776}

Submitted on 5 Jul 2021

HAL is a multi-disciplinary open access archive for the deposit and dissemination of scientific research documents, whether they are published or not. The documents may come from teaching and research institutions in France or abroad, or from public or private research centers.
L'archive ouverte pluridisciplinaire HAL, est destinée au dépôt et à la diffusion de documents scientifiques de niveau recherche, publiés ou non, émanant des établissements d'enseignement et de recherche français ou étrangers, des laboratoires publics ou privés. 


\title{
Numerical Intelligence for Mobility and Communication: Tendencies in Automatics and Control
}

\author{
Vincent Vigneron: Université d’Evry Val d’Essonne, IBISC-lab, Courcouronnes, France, Tel.: (+33/0) 169477500 , \\ e-mail: vincent.vigneron@ibisc.univ-evry.fr \\ Dominique Gruyer: IFSTTAR-LIVIC, Versailles-Satory, France, Tel.: (+33/0) 130844 007, e-mail: dominique.gruyer@ifsttar.fr \\ Said Mammar: Université d'Evry Val d'Essonne, IBISC-lab, Courcouronnes, France, Tel.: (+33/0) 169470606 , \\ e-mail: said.mammar@ibisc.univ-evry.fr
}

Since the 1980s, intelligent systems have been at the core of numerous developments and very active new areas of research. New algorithms and theoretical approaches have emerged to solve a set of new problems and issues, including multisensor fusion, environment perception, cooperative devices with wireless sensor in both high-speed networks and networks with great data load, distributed computer systems, and dynamical networks.

It is often unknown or neglected that the real-time command and control of complex systems are often limited to only some specific and given conditions. However, in real-world and real-time applications, these complex systems encounter very different working conditions that influence their operating characteristics and their behaviors. These configurations may unfortunately lead to errors, critical states, or failures [2, 3]. Moreover, these systems, often non-linear, have high-frequency operating characteristics with continuously changing specifications. In the presence of dysfunctions and failures, the stage of performance evaluation and quality characterization of an intelligent system becomes much more difficult. Thus, the management of the complex systems in these critical situations is becoming a major concern in order either to detect the failure states or to take into account specific strategies to limit their impacts.

The 2013 10th IEEE International Conference on Networking, Sensing and Control, which took place in University of Evry Val-d'Essonne, Evry, France, from April 10 to 12, 2013, gathered the leading world experts in information and signal transmission networks, energy and water distribution networks, goods and people transportation networks, and control of networks to present and discuss the latest developments in this field of research. Articles of the present special issue (SI) have been written by scientists dealing with challenging problems of data modeling and data processing needed in order to efficiently handle complex and intelligent systems.

To design and implement control mechanisms for monitoring networks, intelligent methods have been used, for instance in the following applications [1]:

- Control of urban wastewater networks,

- Control of complex robots,

- Situational control for autonomous driving,

- Real-time perceptive measurements for embedded assistance systems.

To achieve these objectives, the latest communication technologies have been incorporated into heterogeneous networks of sensors and data sources that allow the fast deployment of dedicated and efficient solutions. These technologies also allow steps and strategies to be taken in case of emergency and critical situations. This is mainly the case in safe and critical applications used in military, aerospace, and industrial domains. These technologies lead to make reliable and robust intelligent platforms for processing and management of data [4]. For instance, reliable navigation systems include safe path planning task, obstacles detection, identification, and avoidance modules, and sensor-based motion estimation in order to maintain a high guaranteed level of availability and safety. Hardware resources, information systems, and human factors (managers, users) create a mix of stochastic and deterministic events that are often interdependent. Meanwhile, it is very often difficult to find a relation between system components and system events - or, in other words, the relation between the cause and the effect. It is even more difficult to define a relevant mathematical modeling with analytical formulation that represent such phenomena as, for instance, a user mistake and the system 
response delay. Of course, these problems are not only associated with human factors but the same difficulties are also generated by complex information system resources. These problems may only be solved by using artificial intelligence and applied mathematical methods [3, 5].

In the following, we are presenting the seven articles selected for this SI that contribute to diverse facets of intelligent control and information technology. We believe that the state-of-the art studies presented in this SI will be very useful to a broad readership.

The first two articles are devoted to theoretical issues. These include a hybrid model-based approach implemented with an adaptive fuzzy wavelet network (Yusuf and Sevcan), and mining time-series data from angle-based dissimilarity to discover formation mechanisms in an online social network (Zhou and Zhao).

The article of Duviella et al. presents a gray-box state-space modeling approach of an inland navigation reach. It requires a good estimation of the time delays characterizing the dynamics of the open-channel system.

The three following articles investigate different aspects of situational control and modeling for navigation robotics, including motion control for humanoid robot in indoor and outdoor environments involving obstacles (Wirbel, Steux, Bonnabel, and De LaFortelle); how to manage conflict and ambiguities in map-matching (Gruyer, Belaroussi, Cord, and Vigneron); and an outline on multisensor data fusion with uncertainty that can be modeled in different ways with probability and multiobjective optimization - e.g., with the weighted sum technique (Abdulhafiz and Khamis). This is of crucial importance for mobile robot local positioning. The last article of this SI, proposed by Zdjiga, Ichalal, Ait Oufroukh, and Mammar, includes recent results of a non-linear Takagi-Sugeno vehicle model for state and road curvature estimation.

Conventionally, the control purpose is to design a control system such that the system output can track a desired trajectory signal, $\mathbf{y}^{\star} \in \mathbb{R}^{m}$. Define the tracking error as $\mathbf{e}=\mathbf{y}^{\star}-\mathbf{y}$. The objective of the control design is to minimize the tracking error. The system output shall make decisions also with sufficient time to deal effectively with critical situations such as vehicle rollover or flooding of a wastewater system. If for a given model of the form $\mathbf{x}=f(\underline{\mathbf{x}})+G(\underline{\mathbf{x}}) \mathbf{u}+L(\underline{\mathbf{x}})$, where $\mathbf{x} \in \mathrm{R}^{m}$ is the state, $\underline{\mathbf{x}}=\left[\mathbf{x}^{T}, \dot{\mathbf{x}}^{T}, \ddot{\mathbf{x}}^{T}, \ldots, \mathbf{x}^{(n)^{T}}\right]^{T} \in \mathbb{R}^{m}, \mathbf{u} \in \mathbb{R}^{m}$ is the control input, there exist miss-modelings $L(\cdot)$ between practical systems and the nominal functions, they can be absorbed into the uncertainty. This strategy guided the works of Wirbel et al. and of Abdulhafiz and Khamis.

In many situations, systems are often limited to control a complex system only at some given conditions, and find themselves in very different working conditions, which influence the parameters of their operation and characteristics of behavior and may lead to errors and critical states. Owing to the limitation of the number of control algorithms, it is necessary to limit the number of operational situations so that control strategies would cover all operational situations by getting toward a classification of situations. Usually, one control strategy covers one situational class. The models proposed in Gruyer et al. for advanced driver assistance systems and in Yusuf and Sevcan were designed for the control of complex systems, for which the traditional cybernetic models were not sufficient. Owing to multiple regimes of control and also to the highdimensional high-parametric dynamics of the system to be controlled, it is today necessary to consider the use of robust intelligent methods for these tasks.

As guest editors, we would like to thank Professor Hasan Fleyeh for providing the opportunity to prepare this SI. We also thank all the authors and the reviewers for their hard work. We hope this SI will stimulate further research into the exciting field of intelligent control and sensor networks.

\section{Bibliography}

[1] B. G. Djasow, Y. V. Mironov and N. I. Jusupowa, Models of controlled objects critical regimes prevention is uncertain conditions, preprint of Russian Academy of Sciences, Ufa, Russia (2002).

[2] T. V. Perraju, Specifying fault tolerance in mission critical intelligent systems, Knowl.-Based Syst. 14 (2001), 385-396.

[3] V. M. Sempere-Paya and S. Santonja-Climent, Integrated sensor and management system for urban waste water networks and prevention of critical situations, Comput. Environ. Urban 36 (2012), 65-80.

[4] Special Issue on Dependability of AI Systems, IEEE transactions on knowledge and data engineering, 1995.

[5] W. Zamojski, J. Kacprzyk, J. Mazurkiewicz, J. Sugier and T. Walkowiakn, editors, Dependable computer systems, vol. 97 of Advances in Intelligent and Soft Computing, Springer-Verlag, Berlin, 2011. 